Tohoku J. Exp. Med., 1990, 162, 1-13

\title{
Normal Human Epidermal Keratinocyte-Derived Neutrophil Chemotactic Factor
}

\author{
Hideaki Takematsu, Noriko Isono, * Taizo Kato and \\ Hachiro Tagami \\ Department of Dermatology, Tohoku University School of \\ Medicine, and *Department of Microbiology, Tohoku \\ University School of Dentistry, Sendai 980
}

\begin{abstract}
Takematsu, H., Isono, N., Kato, T. and Tagami, H. Normal Human Epidermal Keratinocyte-Derived Neutrophil Chemotactic Factor. Tohoku J. Exp. Med., 1990, 162 (1), 1-13— Human epidermal keratinocytes constitutively produce a variety of cytokines, including neutrophil chemotactic peptide named epidermal cell-derived thymocyte-activating factor, which has been later confirmed to be interleukin 1 (IL-1). Because recombinant IL-1 lacks chemotactic activity, in the present study, we examined the exact nature of the neutrophil chemotactic peptide in the culture supernatant of normal human epidermal keratinocytes. Normal human epidermal keratinocytes produced a neutrophil chemotactic factor, which was also chemotactic for T lymphocytes. Molecular sieve chromatography revealed an approximate molecular size of 11,000 daltons. The activity was retained after heating at $100^{\circ} \mathrm{C}$ for $10 \mathrm{~min}$, and at a $\mathrm{pH}$ between 4 and 11 , but was partially inactivated at $\mathrm{pH} 3$, or by trypsin treatment. The chemotactic activity was not inhibited by the treatment with anti-IL-1 antibody. Its production by keratinocytes was stimulated by IL-1 and lipopolysaccharide but not by UV irradiation, tumor necrosis factor- $\alpha$ or by interferon- $\gamma$. The neutrophil chemotactic activity in vivo was confirmed by the intradermal injection of the factor into guinea pigs. Blocking study with monoclonal antibodies against NAP-1/IL-8 confirmed that the neutrophil chemotactic factor is IL-8.

keratinocyte; chemotactic factor; interleukin 8
\end{abstract}

Inflammatory reactions in skin diseases such as psoriasis are mediated by cytokines produced by epidermal keratinocytes (Takematsu et al. 1986a, b ; Elder et al. 1989; Grossman et al. 1989; Kupper 1989; Takematsu and Tagami 1990); human epidermal keratinocytes constitutively produce a variety of cytokines, including interleukin 1 (IL-1) (Luger et al. 1983b ; Sauder et al. 1983 ; Hauser et al. 1986 ; Kupper et al. 1986), IL-3 (Danner and Luger 1987), IL-6 (Grossman et al. 1989), transforming growth factor $\alpha$ (Coffey et al. 1987), $\beta$ (Fisher et al. 1988), and granulocyte-macrophage colony-stimulating factor (Chodakewitz et al. 1988).

One of the salient histologic features of psoriatic lesions is an accumulation of neutrophils in intra- and subcorneal or spongiform pustules (Ackerman

Received January 25, 1990 ; revision accepted for publication August 10, 1990. 
et al. 1982). Previously, we suggested the presence of 12,000 Da chemotactic peptides other than anaphylatoxin C5a in psoriatic lesional skin (Takematsu et al. 1986a). Production of a neutrophil chemokinetic peptide was also supposed from the presence of chemoattractant activity in the stratum corneum of psoriatic skin lesions (Fincham et al. 1988; Schröder et al. 1989). Neutrophil chemotactic peptides have been found to be produced by a variety of cells including macrophages (Kownatzki et al. 1986 ; Schröder et al. 1987; Yoshimura et al. 1987 ; Matsushima et al. 1988), lymphocytes (Schröder et al. 1988), endothelial cells (Strieter et al. 1989a), and fibroblasts (Strieter et al. 1989b). On the other hand, there has been scant direct evidence to show that a neutrophil chemotactic factor is produced by normal human epidermal keratinocytes except for epidermal cell-derived thymocyte-activating factor (ETAF) that shows the activity of IL-1 (Luger et al. 1983b).

The purpose of this study was to examine neutrophil chemotactic properties of the culture supernatant of normal human epidermal keratinocytes, particularly in relation to IL-1. We present here direct evidence to support the concept that normal human keratinocytes produce a neutrophil chemotactic factor IL-8.

\section{Materials and Methods}

Chemicals. The following materials were purchased from Sigma Chemical Company (St. Louis, MO, USA) : trypsin-Agarose beads; mouse IgG; Agarose beads coated with rabbit IgG; phorbor 12-myristate 13-acetate (PMA); protein A-Sepharose CL-4B. EpiPack's Normal Human Epidermal Keratinocytes and Keratinocyte Growth Medium were from Clonetic Corporation, San Diego, CA, USA. MCDB153 from Kyokuto Pharmaceutical Company, Tokyo, Japan. Uni-Pore polycarbonate membrane was from Bio-Rad Laboratories, Richmond, CA, USA, and nitrocellulose membrane was from Nihon Millipore Kogyo, Yonezawa, Japan. Human T-Cell Recovery Column was from Scican Diagnostics, Alberta, Canada. Human recombinant (r) IL- $1 \alpha$ and $\beta$, human recombinant tumor necrosis factor- $\alpha$, human recombinant interferon- $\gamma$, human r-granulocyte-macrophage colonystimulating factor (GM-CSF) were from Genzyme Corporation, Boston, MA, USA. Lipopolysaccharide (LPS; E. coli 055: B5) was from Difco Laboratories, Detroit, MI, USA.

Antibodies. Rabbit anti-human IL-1 antibody was from Genzyme Corporation, Boston, MA, USA. Monoclonal antibody against NAP-1 was a gift from Dr. T. Yoshimura (Immunopathology Section, Laboratory of Immunobiology, National Cancer Institutue, Frederick, MD, USA), and monoclonal antibody against NAP-1/IL-8, 46ES was from Dr. Schröder (Department of Dermatology, University of Kiel, Kiel, Germany).

Cell culture. Normal human epidermal keratinocytes were grown in Keratinocyte Growth Medium. After appropriate culture time, the conditioned medium was collected.

Molecular sieve chromatography. Culture supernatant of normal epidermal keratinocytes was loaded onto a TSK-G2000SW exclusion high performance liquid chromatography column (Tosoh, Tokyo $; 7.5 \times 30 \mathrm{~cm}$ ). Phosphate-buffered saline was used as the eluent. Flow rate was $0.5 \mathrm{ml} / \mathrm{min}$, and fractions of $0.5 \mathrm{ml}$ were collected. The protein content was estimated by the measurement of absorbance at $280 \mathrm{~nm}$. The fractions were assayed for neutrophil chemotactic activity.

Temperature stability. The column fraction was subjected to heating for $30 \mathrm{~min}$ at $60^{\circ} \mathrm{C}$, for $10 \mathrm{~min}$ at $100^{\circ} \mathrm{C}$, or repeated freeze/thawing three times. 
$p H$ treatment. $\mathrm{pH}$ of the column fraction was altered for $1 \mathrm{hr}$ then adjusted to $\mathrm{pH} 7.4$, and tested for neutrophil chemotactic activity.

Trypsin sensitivity. The column fraction $(400 \mu \mathrm{l})$ was incubated for $5 \mathrm{~min}$ at $34^{\circ} \mathrm{C}$ with $100 \mu$ l of trypsin-Agarose beads ( 5 units) or $100 \mu$ l of Agarose beads coated with rabbit IgG. The beads were removed by centrifugation, and the supernatants were assayed for chemotactic activity (Sheridan et al. 1987).

Blocking studies. To assess the relationship between the neutrophil chemotactic factor and IL-1, blocking study was performed. Rabbit anti-human IL-1 antibody or an IgG fraction of normal rabbit serum was incubated with the neutrophil chemotactic fraction for $2 \mathrm{hr}$ at room temperature followed by $48 \mathrm{hr}$ at $4^{\circ} \mathrm{C}$. Samples were then centrifuged at $2,000 \times \mathrm{g}$ for $30 \mathrm{~min}$ at $4^{\circ} \mathrm{C}$, and the supernatant was then assayed for chemotactic activity.

To assess the relationship between the neutrophil chemotactic factor and IL-8, blocking study was performed. Neutrophil chemotactic fraction was incubated with monoclonal antibody against NAP-1, monoclonal antibody against NAP-1/IL-8, or mouse IgG adsorbed to protein A-Sepharose CL-4B at for $1 \mathrm{hr}$ at room temperature. Samples were then centrifuged at $2,000 \times g$ for $10 \mathrm{~min}$ at $4^{\circ} \mathrm{C}$, and the supernatant was then assayed for chemotactic activity.

Effect of cytokines, PMA and LPA. Normal human epidermal keratinocytes were stimulated with $100 \mathrm{U} / \mathrm{ml}$ human rIL- $1 \alpha, 100 \mathrm{U} / \mathrm{ml}$ human rIL- $1 \beta, 100 \mathrm{U} / \mathrm{ml}$ rTNF- $\alpha, 100$ $\mathrm{U} / \mathrm{ml}$ human rIFN- $\gamma, 60 \mathrm{U} / \mathrm{ml} \mathrm{rhGM}-\mathrm{CSF}, 1 \mathrm{ng} / \mathrm{ml} \mathrm{PMA}$, and $10 \mu \mathrm{g} / \mathrm{ml}$ LPS in MCDB153 medium. After stimulation for $24 \mathrm{hr}$ (Matsushima et al. 1988), the chemotactic activities in the culture supernatants were assayed.

$U V$ irradiation. Normal human keratinocytes were irradiated with $0,25,50$, and 200 $\mathrm{J} / \mathrm{m}^{2}$ of ultraviolet (UV) light in the 280 - to 320 -nm range by a FL 20 S fluorescent sun lamp (Matsushita Electric Company, Tokyo). Neutrophil chemotactic activity in the culture supernatant was assayed $24 \mathrm{hr}$ after UV irradiation (Gahring et al. 1984).

Synergism with $\mathrm{C} 5 \mathrm{a} / \mathrm{C} 5 \mathrm{a}$ des $\mathrm{Arg}$. In order to assess the synergism with chemotactic complement fragment C5a/C5a des Arg, the column fraction was tested for neutrophil chemotactic activity in the presence or absence of equal amount of a fraction of zymosanactivated serum containing C5a/C5a des Arg (Takematsu et al. 1986b). After incubating for $30 \mathrm{~min}$, neutrophil chemotactic activities in the samples were assayed.

Neutrophil chemotactic assay. Neutrophil chemotactic activity was measured using a Blind Well Chamber with a $3-\mu \mathrm{m}$ Uni-Pore polycarbonate membrane. Human neutrophils collected after centrifugation of heparinized blood on Ficoll-Isopaque solution were suspended in Hanks' solution containing $0.5 \%$ bovine serum albumin and $100 \mu \mathrm{g} / \mathrm{ml}$ streptomycin. A suspension containing $2 \times 105$ cells in $30 \mu \mathrm{l}$ was placed in the upper compartment of the chamber, while $25 \mu \mathrm{l}$ of a chemoattractant was placed in the bottom compartment. The chamber was incubated for $45 \mathrm{~min}$ at $37^{\circ} \mathrm{C}$ in a $5 \% \quad \mathrm{CO}_{2}$ moist atmosphere. The chemotactic activity was expressed as an average number of the cells reaching the bottom surface of the filter in five fields for each filter at a magnification of $\times 400$.

Lymphocyte chemotactic assay. In lymphocyte chemotactic assay, a stimulus was placed in the lower compartment of a chemotactic chamber, and human T-lymphocyte suspension $\left(2 \times 10^{6} / \mathrm{ml}\right)$ obtained through Human T-Cell Recovery Column was poured into the upper compartment, separated by a $5 \mu \mathrm{m}$-pore size nitrocellulose membrane. After incubation of the chambers for $3 \mathrm{hr}$ at $37^{\circ} \mathrm{C}$, the membranes were detached, stained with Giemsa, and cleared with xylene. Cell migration was assessed by the leading front technique : measurement of distances that the leading 2 cells moved through the membrane; a migration index was defined as the difference between movements in response to the medium alone and in response to a stimulus (Okamoto et al. 1985).

Chemiluminescence assay. The chemiluminescence assay was performed by using a Biolumat (LB9500, Berthold, FRG) as described previously (Kato et al. 1983).

Thymocyte assay of $I L-1$. IL-1 activity was assessed by potentiation of thymocyte reactions to a mitogen (comitogenic assay) (Luger et al. 1983b). Mouse thymocytes were 
suspended in RPMI 1640 containing $10 \%$ fetal calf serum and cultured for $72 \mathrm{hr}$ at $1.5 \times 10^{6}$ cells $/ 0.2 \mathrm{ml} /$ well in flat-bottomed microtiter plates (Falcon, Becton Dickinson Labware, Lincoln Park, NJ, USA). Cultures were pulsed with $0.5 \mu \mathrm{Ci} /$ well of $\left[{ }^{3} \mathrm{H}\right]$ thymidine (specific activity, $5.0 \mathrm{Ci} / \mathrm{mmol}$ ) for the final $16 \mathrm{hr}$ of incubation. Cells were collected on glass filter paper by an automatic cell microharvester and $\left[{ }^{3} \mathrm{H}\right]$ activity was counted by a liquid scintillation counter.

Intradermal injection. A suspension of the column fractions in $100 \mu$ l collected through molecular sieve chromatography was injected intradermally into the skin of back of guinea pigs. A $3 \mathrm{~mm}$ punch biopsy was performed $0,1,2,3$, and $6 \mathrm{hr}$ after the injection. All biopsies were processed for light microscopy, and hematoxylin and eosin-stained sections were examined.

\section{RESULTS}

\section{Kinetics}

The conditioned medium of the normal human keratinocyte showed a neutrophil chemotactic activity (Fig. 1). The chemotactic activity was mainly produced at the logarithmic growth phase of the cells.

\section{Molecular sieve chromatography}

Characterization by molecular sieve chromatography revealed that the culture supernatant of the normal human keratinocyte had neutrophil chemotactic activity in the fraction with an approximate mol. wt. of 11,000 (Fig. 2). The 11,000 dalton fraction thus obtained was pooled and used in the following experiments.

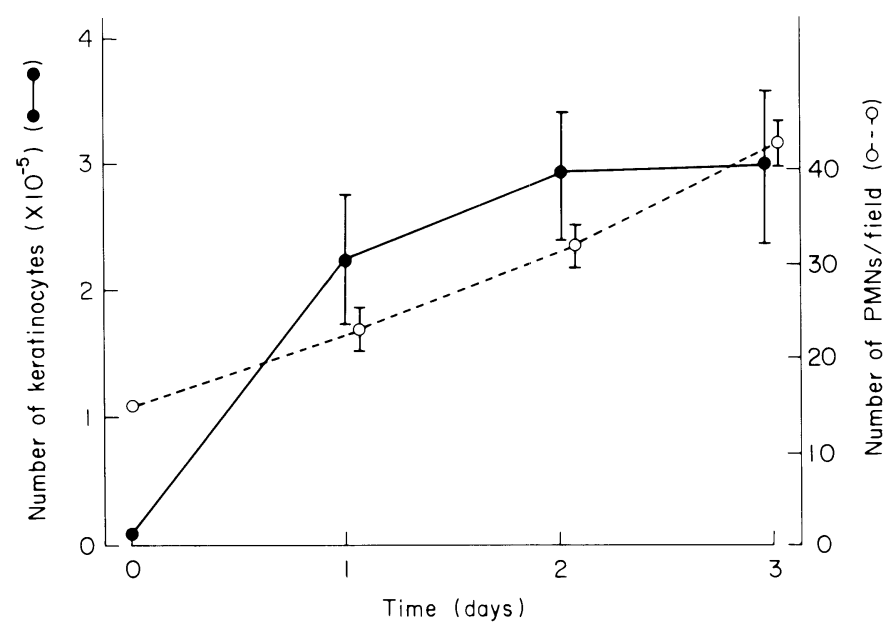

Fig. 1. Kinetics of production of the neutrophil chemotactic factor. Normal human epidermal keratinocytes were grown. After the indicated time, the numbers of cells were counted, and neutrophil chemotactic activity in the culture supernatant was assayed. Data are means \pm S.E. from six replicate determinations. 


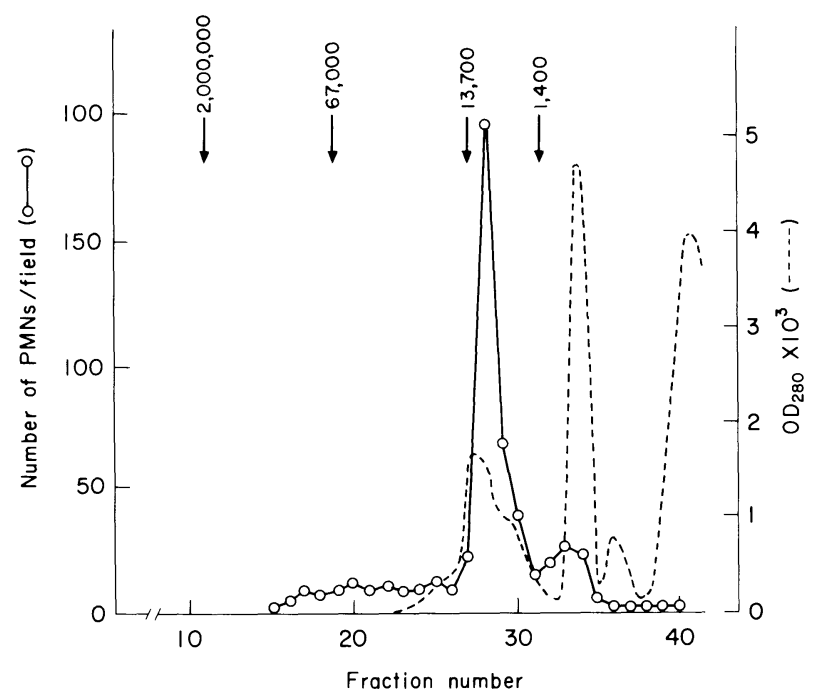

Fig. 2. Molecular sieve chromatography of the keratinocyte-derived neutrophil chemotactic factor. Culture supernatant of normal epidermal keratinocytes was loaded onto a TSK-G2000SW gel filtration colum $(7.5 \times 30 \mathrm{~cm})$. Phosphate-buffered saline was used as the eluent. The fraction size was 0.5 $\mathrm{ml}$, and the flow rate was $0.5 \mathrm{ml} / \mathrm{min}$. The protein content was estimated by the measurement of absorbance at $280 \mathrm{~nm}$. The fractions were assayed for neutrophil chemotactic activity.

Chemotactic and chemokinetic activity

Checkerboard analysis revealed that the peak fraction of the factor collected through the molecular sieve chromatography was predominantly chemotactic but mildly chemokinetic for neutrophils (Table 1).

\section{$T$ lymphocyte chemotactic activity}

The keratinocyte-derived factor was also mildly chemotactic but less chemokinetic for $\mathrm{T}$ lymphocytes (Table 2).

\section{Temperature stability}

Studies of the effect of temperature on the stability of the neutrophil chemotactic factor revealed that heating at $60^{\circ} \mathrm{C}, 100^{\circ} \mathrm{C}$, or repeated freeze/thawing had no effect on the neutrophil chemotactic factor activity (data not shown).

pH stability

When the neutrophil chemotactic factor was tested for $\mathrm{pH}$ stability, the activity was stable from $\mathrm{pH} 4$ to 11 . Acid $\mathrm{pH}$ of 3 partially inactivated the neutrophil chemotactic activity (from $155 \pm 9$ to $80 \pm 6$ ). 
TABLE 1. Chemokinetic and chemotactic activity of the keratinocyte-derived factor for neutrophils ${ }^{a}$

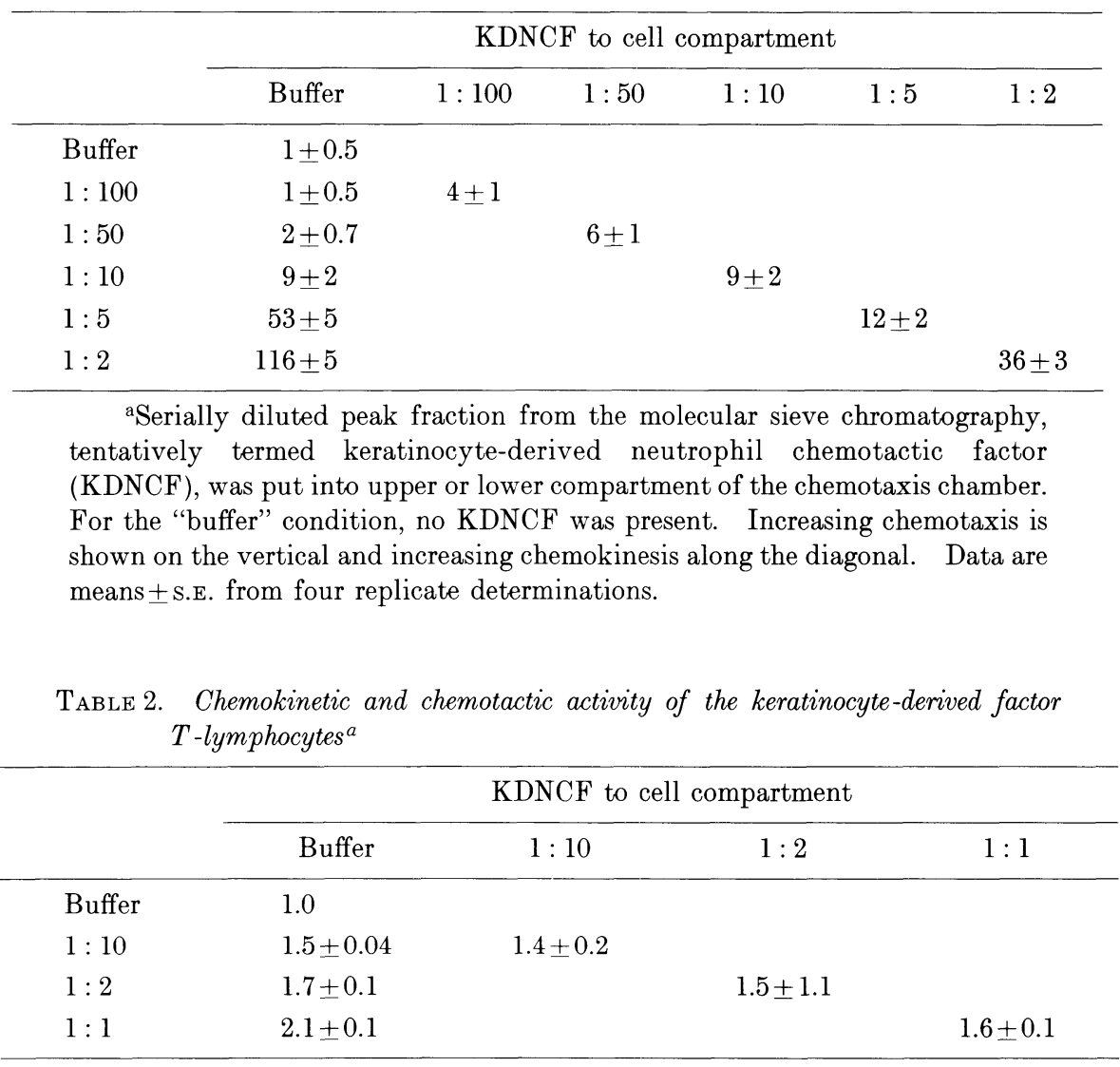

aSerially diluted KDNCF was put into upper or lower compartment of the chemotaxis chamber. Data are means \pm s.E. from four replicate determinations.

\section{Trypsin sensitivity}

Treatment with trypsin significantly reduced the activity of the neutrophil chemotactic factor (from $125 \pm 11$ to $30 \pm 5$ ).

\section{Effect of antibody to human $I L-1$}

Rabbit anti-human IL-1 antibody was found to inhibit the action of recombinant IL- $1 \alpha$ and in the thymocyte assay. The chemotactic activity was not inhibited by the treatment with the anti-IL-1 antibody, indicating that the neutrophil chemotactic factor is antigenically distinct from IL- $\alpha$ and $\beta$ (data not shown). 
TABLE 3. Effect of monoclonal antibodies against NAP-1/ $I L-8$ on the activity of the neutrohil chemotactic activity ${ }^{a}$

\begin{tabular}{lc}
\hline Treatment & Chemotactic activity \\
\hline Mouse IgG & $102 \pm 9$ \\
Anti-NAP-1 & $25 \pm 3$ \\
$46 E S$ & $20 \pm 2$ \\
\hline
\end{tabular}

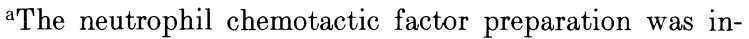
cubated with monoclonal antibodies against NAP-1/IL-8 or mouse IgG adsorbed to protein A-Sepharose CL-4B at for $1 \mathrm{hr}$ at room temperature, and the supernatant was then assayed for neutrophil chemotactic activity. Data are means \pm s.E. from six replicate determinations.

\section{Effect of antibody against NAP-1/IL-8}

Monoclonal antibodies against NAP-1/IL- 8 inhibited the activity of the neutrophil chemotac activity (Table 3 ).

\section{Effect of cytokines, PMA and LPS}

Treatment with the cytokines did not induce specific proliferation of the keratinocytes. IL- $1 \alpha$ and $\beta$ stimulated the production of the neutrophilc

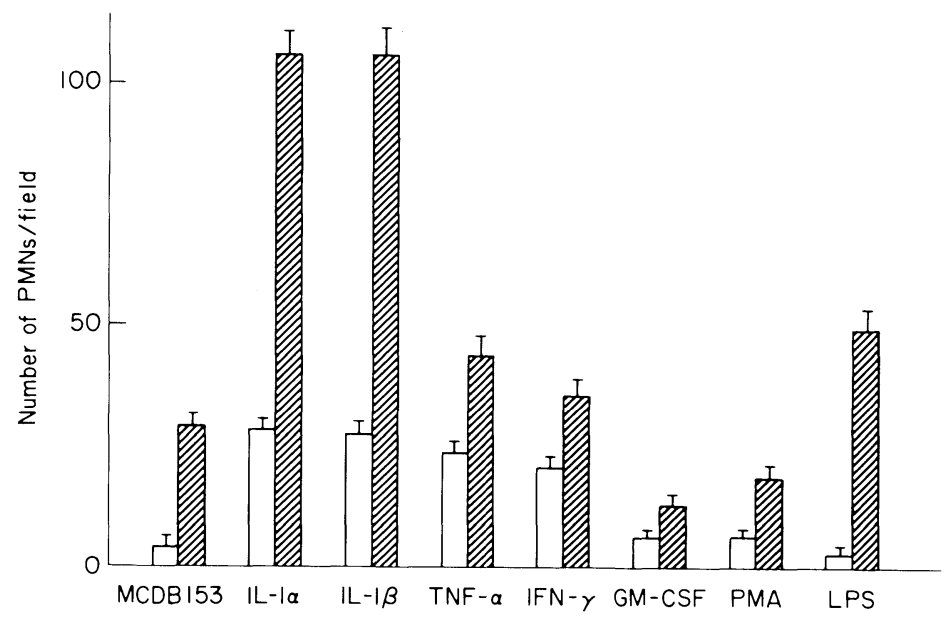

Fig. 3. Stimulation of production by cytokines. Normal human keratinocytes were incubated with MCDB153 medium, human (h) rIL-1 $\alpha, \beta$, hrTNF- $\alpha$, hrIFN- $\gamma$, hrGM-CSF, PMA, and LPS in MCDB153. After stimulation for 24 $\mathrm{hr}$, the neutrophilic chemotactic activities of the stimulators (open columns) and those of the culture supernatants (shaded columns) were measured. Data are means \pm s.E. from six replicate determinations. 
chemotactic factor, and LPS augmented chemotactic factor production, while TNF- $\alpha$ IFN- $\gamma$, GM-CSF, or PMA did not at the concentrations tested (Fig. 3).

\section{Effect of $U V$ irradiation}

When the normal human keratinocytes were irradiated with 25, 50, and 200 $\mathrm{J} / \mathrm{m}^{2}$ of UV light in the 280 - to $320-\mathrm{nm}$ range, there was no significant increase in the neutrophil chemotactic activity in the culture supernatant (data not shown).

\section{Synergim with C5a/C5a des Arg}

A mixture of the neutrophil chemotactic factor and C5a/C5a des Arg showed a much higher neutrophil chemotactic activity than the sum of the activities of the chemotactic factor and that of C5a/C5a des Arg, suggesting a synergism between the neutrophil chemotactic factor and C5a/C5a des Arg (Fig. 4).

\section{Chemiluminescence assay}

The neutrophil chemotactic factor had no effect on the oxidative metabolism of neutrophils as measured by chemiluminescence (data not shown).

\section{Intradermal injection}

Intradermal injection of the neutrophil chemotactic factor into guinea pigs induced an accumulation of neutrophils and mononuclera cells in the dermis and within the blood vessels 3 to $6 \mathrm{hr}$ after injection (Fig. 5).

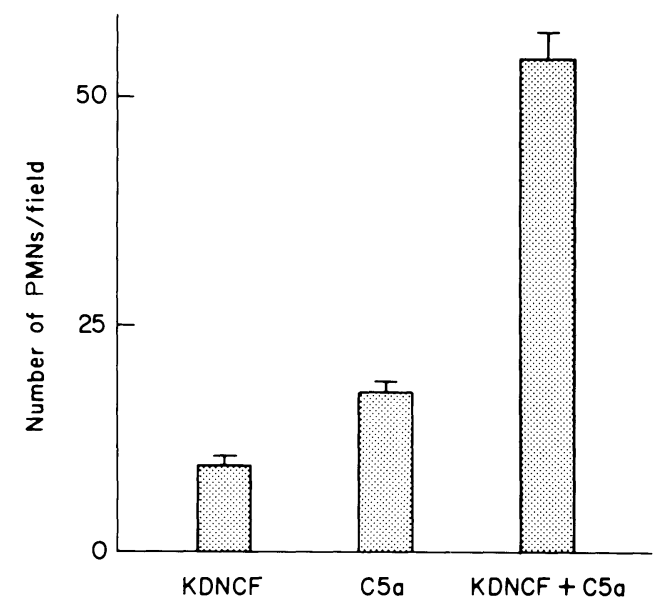

Fig. 4. Synergism of the neutrophil chemotactic factor and C5a/C5a des Arg. The neutrophil chemotactic factor were tested for neutrophil chemotactic activity in the presence or absence of equal amount of a fraction of zymosanactivated serum containing C5a/C5a des Arg. Data are means \pm s.E. from six replicate determinations. 


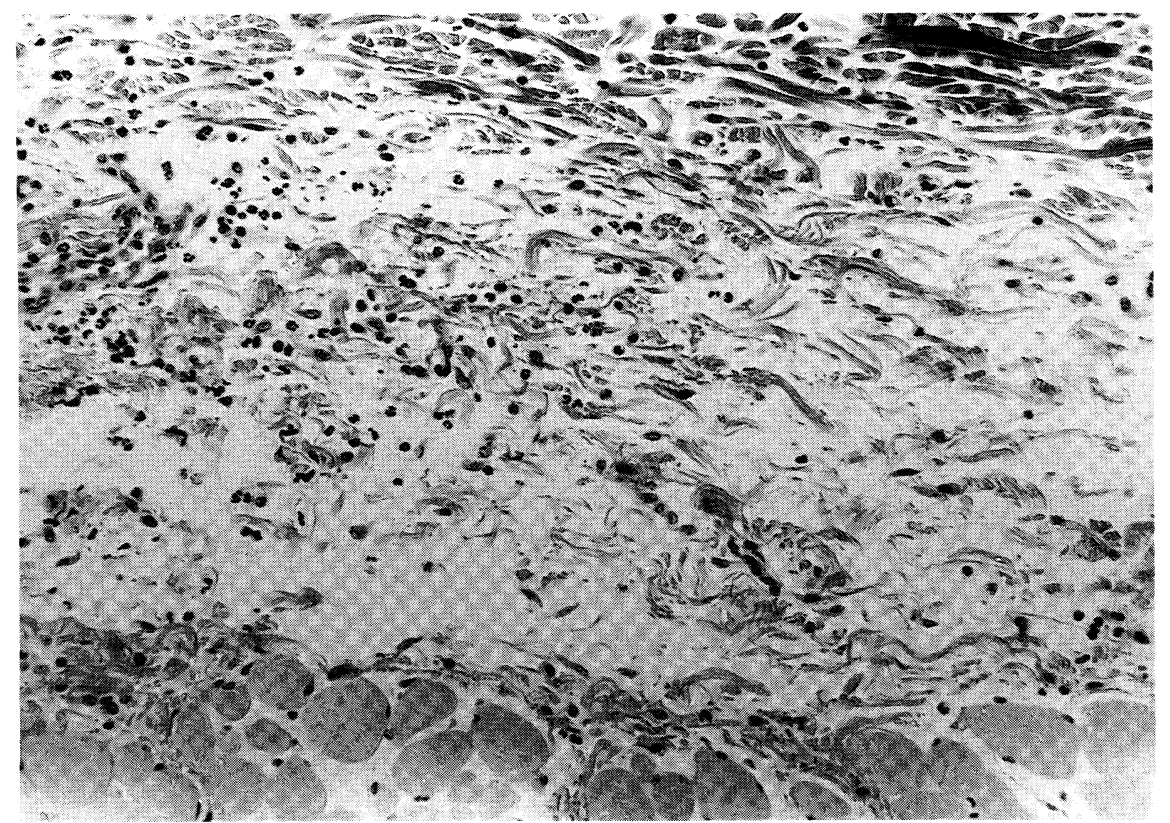

Fig. 5. Intradermal injection. Intradermal injection of the neutrophil chemotactic factor into guinea pigs induced an accumulation of neutrophils and mononuclear cells in the dermis.

\section{Discussion}

Neutrophil chemotactic peptides have been found to be produced by epidermal cells as well as by inflammatory cells (Schröder et al. 1987 ; Yoshimura et al. 1987 ; Strieter et al. 1989a, b; Watanabe et al. 1989). In the present study we showed that normal human epidermal keratinocytes produced in vitro a neutrophil chemotactic factor, which was also chemotactic for $\mathrm{T}$ lymphocytes. The activity was produced predominantly at the logarithmic growth phase. Molecular sieve chromatography revealed an approximate molecular size of 11,000 daltons. The activity was retained after heating at $100^{\circ} \mathrm{C}$ for $10 \mathrm{~min}$, and at a $\mathrm{pH}$ between 4 and 11, but was partially inactivated at $\mathrm{pH} 3$, or by trypsin treatment. The chemotactic activity was not inhibited by the treatment with anti-IL-1 antibody. Its production by keratinocytes was stimulated by IL-1 but not by UV irradiation. Its in vivo neutrophil chemotactic activity was confirmed by the intradermal injection of the factor into guinea pigs. These results suggest that human keratinocytes are capable of producing a neutrophil chemotactic peptide distinct from IL-1.

Previously, ETAF with an approximate mol wt of 12,000 Da that was indistinguishable from IL-1, was shown to be chemotactic for neutrophils (Luger et al. 1983a; Sauder et al. 1984). Although later, rIL-1 itself was shown to lack 
chemotactic activity (Yoshimura et al. 1987), no studies have been done on the nature of the chemotactic peptides reported as ETAF. Our present study showing the distinction of the keratinocyte-derived neutrophil chemotactic factor from IL-1 clearly indicates that the concurrent expression of both IL-1-like and neutrophil chemotactic activities in ETAF preparation seems to be due to the incomplete dissociation of IL-1 in the past from the neutrophil chemotactic factor in the column fractions as once suggested by Yoshimura et al. (1987). Gahring et al. (1984) showed that UV irradiation enhanced the release of ETAF/IL-1. In the present study, however, we found no effect of UV light on the production of the neutrophil chemotactic activity. Again, this discrepancy seems to be due to the difference in the release mode of IL-1 and the chemotactic peptide by keratinocytes. Sauder et al. (1988) showed that ETAF preparation stimulated the autocrine growth of human keratinocytes. Whether this stimulatory effect was due to IL-1 or to the neutrophil chemotactic factor is yet to be clarified.

A neutrophil chemotactic peptide with a mol wt of 9,000 Da produced by macrophages (Kownatzki et al. 1986; Schröder et al. 1987; Yoshimura et al. 1987 ; Matsushima et al. 1988), lymphocytes (Schröder et al. 1988), endothelial cells (Strieter et al. 1989a), and fibroblasts (Strieter et al. 1989b) has been termed IL-8/neutrophil-activating peptide (NAP)-1, and its genomic structure has been determined (Matsushima et al. 1988; Mukaida et al. 1989 ; van Damme et al. 1989). It is chemotactic for both neutrophils and $\mathrm{T}$ lymphocytes (Larsen et al. 1989a). The physicochemical and biochemical characteristics of the keratinocyte-derived neutrophil chemotactic factor demonstrated in the present study suggest that IL- 8 seems to be the most likely candidate for it. Our subsequent blocking study with monoclonal antibodies against NAP-1/IL-8 confirmed that the neutrophil chemotactic factor is IL-8. Our present data are consistent with the recent report by Larsen et al (1989b) on an induction of expression of mRNA for IL-8 in normal human keratinocytes.

While Matsushima et al. (1988) showed the induction of IL-8 mRNA by TNF- $\alpha$ as well as IL-1 in monocytes, we failed to stimulate the production of the neutrophil chemotactic factor by TNF- $\alpha$. Whether the discrepancy was due to the difference in utilized cell source, i.e., monocytes vs keratinocytes, or in method, i.e., mRNA vs peptide, awaits further study.

Inflammatory reactions in the epidermis seem to be intricately regulated, because, although normal keratinocytes secrete neutrophil chemotactic factor in vitro, we see scant infiltration of neutrophils and mononuclear cells into the normal epidermis in vivo. In addition to IL-1, normal human epidermal keratinocytes were found to produce an inhibitor of IL-1 (Takematsu et al. submitted). It is, therefore, intriguing to speculate whether, in the same fasion, normal human epidermal keratinocytes produce inhibitor(s) of the neutrophil chemotactic factor in vivo, thereby suppressing the inflammatory reactions in the epidermis.

Based on the results of our present study and those of others (Hauser et al. 
1986), we can conclude that normal human epidermal keratinocytes constitutively produce IL-1 and IL-8. The levels of IL-I in the psoriatic scales are significantly lower than that in the normal stratum corneum (Takematsu et al. 1986b; Cooper et al. 1990). Thus, it is intriguing to speculate how the production of proinflammatory IL-8 is regulated in the psoriatic lesional skin.

Complement-derived chemotactic factors, C5a/C5a des Arg, is another chemotactic peptide in psoriatic lesional skin (Takematsu et al. 1986a). The synergism of the keratinocyte-derived chemotactic factor with C5a/C5a des Arg observed in the present study suggests that the keratinocyte-derived chemotactic factor and the complement derived factors are capable of augmenting the chemotactic activity each other in the lesional skin of psoriasis or sterile pustular dermatoses.

\section{References}

1) Ackerman, A.B., Niven, J. \& Grant-Kels, J.M. (1982) Differential Diagnosis in Dermatopathology, Lea \& Febiger, Philadelphia.

2) Chodakewitz, J.A., Kupper, T.S. \& Colemen, D.L. (1988) Keratinocyte-derived granulocyte/macrophage colony-stimulating factor induces DNA synthesis by peritoneal macrophages. J. Immunol., 140, 832-836.

3) Coffey, R.J., Jr., Derynck, R., Wilcox, J.N., Bringman, T.S., Goustin, A.S., Moses, H.L. \& Pittelkow, M.R. (1987) Production and auto-induction of transforming growth factor- $\alpha$ in human keratinocytes. Nature, 328, 817-820.

4) Cooper, K.D., Hammerberg, C., Baadsgaard, O., Elder, J.T., Chan, S., Sauder, D.N., Voorhees, J.J. \& Fisher, G. (1990) IL-1 activity is reduced in psoriatic skin: Decreased IL-1 $\alpha$ and increased nonfunctional IL-1 $\beta$. J. Immunol., 144, 4593-4603.

5) Danner, M. \& Luger, T.A. (1987) Human keratinocytes and epidermoid carcinoma cell lines produce a cytokine with interleukin 3-like activity. J. Invest. Dermatol., 88, 353-361.

6) Elder, J.T., Fisher, G.J., Lindquist, P.B., Bennett, G.L., Pittelkow, M.R., Coffey, R.J., Jr., Ellingsworth, L., Derynck, R. \& Voorhees, J.J. (1989) Overexpression of transforming growth factor $\alpha$ in psoriatic epidermis. Science, 243, 811-814.

7) Fincham, N.J., Camp, R.D.R., Gearing, A.J.H., Bird, C.R. \& Cunningham, F.M. (1988) Neutrophil chemoattractant and IL-1-like activity in samples from psoriatic lesions: Further characterization. J. Immunol., 140, 4294-4299.

8) Fisher, G., Elder, J., Voorhees, J., Kowalki, J., Petersen, C., Derynck, R. \& Ellingsworth, L. (1988) Transforming growth factor beta mRNA is expressed in normal and psoriatic epidermis and has similar biological effects on normal and psoriatic lesional keratinocytes. J. Invest. Dermatol., 90, 558. (Abstract)

9) Gahring, L., Baltz, M., Pepys, M.B. \& Daynes, R. (1984) Effect of ultraviolet radiation on production of epidermal cell thymocyte-activating factor/interleukin 1 in vivo and in vitro. Proc. Natl. Acad. Sci. USA, 81, 1198-1202.

10) Grossman, R.M., Krueger, J., Yourish, D., Granelli-Piperno, A., Murphy, D.P., May, L.T., Kupper, T.S., Sehgal, P.B. \& Gottlieb, A.B. (1989) Interleukin 6 is expressed in high levels in psoriatic skin and stimulates proliferation of cultured human keratinocytes. Proc. Natl. Acad. Sci. USA, 86, 6367-6371.

11) Hauser, C., Saurat, J.-H., Schmitt, A., Jaunin, F. \& Dayer, J.-M. (1986) Interleukin 1 is present in normal human epidermis. J. Immunol., 136, 3317-3323.

12) Kato, T., Terui, T. \& Tagami, H. (1983) Effects of HC20-511 (ketotifen) on chemiluminescence of human neutrophils. Inflammation, 9, 45-51. 
13) Kownatzki, E., Kapp, A. \& Uhrich, S. (1986) Novel neutrophil chemotactic factor derived from human peripheral blood mononuclear leukocytes. Clin. Exp. Immunol., 64, 214-222.

14) Kupper, T.S. (1989) Production of cytokines by epithelial tissues : A new model for cutaneous inflammation. Am. J. Dermatopathol., 11, 69-73.

15) Kupper, T.S., Ballard, D.W., Chua, A.O., McGuire, J.S., Flood, P.M., Horowitz, M.C., Langdon, R., Lightfoot, L. \& Gubler, U. (1986) Human keratinocytes contain mRNA indistinguishable from monocyte interleukin $1 \alpha$ and $\beta$ mRNA : Keratinocyte epidermal cell-derived thymocyte activating factor is identical to interleukin $1 . J$. Exp. Med., 164, 2095-2100.

16) Larsen, C.G., Anderson, A.O., Appella, E., Oppenheim, J.J. \& Matsushima, K. (1989a) The neutrophil-activating protein (NAP-1) is also chemotactic for T lymphocytes. Science, 243, 1464-1466.

17) Larsen, C.G., Anderson, A.O., Oppenheim, J.J. \& Matsushima, K. (1989a) Production of interleukin- 8 by human dermal fibroblasts and keratinocytes in response to interleukin-1 or tumour necrosis factor. Immunology, 68, 31-36.

18) Luger, T.A., Charon, J.A., Colot, M., Micksche, M. \& Oppenheim, J.J. (1983a) Chemotactic properties of partially purified human epidermal cell-derived thymocyteactivating factor (ETAF) for polymorphonuclear and mononuclear cells. J. Immunol., 131, 816-820.

19) Luger, T.A., Stadler, B.M., Luger, B.M., Sztein, M.B., Schmidt, J.A., Hawley-Nelson, P., Grabner, G. \& Oppenheim, J.J. (1983b) Characteristics of an epidermal cell thymocyte-activating factor (ETAF) produced by human epidermal cells and a human squamous cell carcinoma cell line. J. Invest. Dermatol., 81, 187-193.

20) Matsushima, K., Morishita, K., Yoshimura, T., Lavu, S., Kobayashi, Y., Lew, W., Appella, E., Kung, H.F., Leonard, E.J. \& Oppenheim, J.J. (1988) Molecular cloning of a human monocyte-derived neutrophil chemotactic factor (MDNCF) and the induction of MDNCF mRNA by interleukin 1 and tumor necrosis factor. J. Exp. Med., 167, 1883-1893.

21) Mukaida, N., Shiroo, M. \& Matsushima, K. (1989) Genomic structure of the human monocyte-derived neutrophil chemotactic factor IL-8. J. Immunol., 143, 1366-1371.

22) Okamoto, H., Takigawa, M. \& Horio, T. (1985) Alteration of lymphocyte functions by 8 -methoxypsoralen and long-wave ultraviolet radiation. I. Suppressive effects of PUVA on T-lymphocyte migration in vitro. J. Invest. Dermatol., 84, 203-205.

23) Sauder, D.N., Noonan, F.P., DeFabo, E.C. \& Katz, S.I. (1983) Ultraviolet radiation inhibits alloantigen presentation by epidermal cells: Partial reversal by the soluble epidermal cell product, epidermal cell-derived thymocyte-activating factor (ETAF). $J$. Invest. Dermatol., 80, 485-489.

24) Sauder, D.N., Mounessa, N.L., Katz, S.I., Dinarello, C.A. \& Gallin, J.I. (1984) Chemotactic cytokines: The role of leukocytic pyrogen and epidermal cell thymocyte-activating factor in neutrophil chemotaxis. J. Immunol., 132, 828-832.

25) Sauder, D.N., Stanulis-Praeger, B.M. \& Gilchrest, B.A. (1988) Autocrine growth stimulation of human keratinocytes by epidermal cell-derived thymocyte-activating factor: Implications for skin aging. Arch. Dermatol. Res., 280, 71-76.

26) Schröder, J.-M., Mrowietz, U., Morita, E. \& Christophers, E. (1987) Purification and partial biochemical characterization of a human monocyte-derived, neutrophilactivating peptide that lacks interleukin 1 activity. J. Immunol., 139, 3474-3483.

27) Schröder, J.-M., Mrowietz, U. \& Christophers, E. (1988) Purification and partial biologic characterization of a human lymphocyte-derived peptide with potent neutrophil-stimulating activity. $J$. Immunol., 140, 3534-3540.

28) Schröder, J.-M., Young, J., Gregory, H. \& Christophers, E. (1989) Aminoacid sequence characterization of two structurally related neutrophil activating peptides obtained from lesional psoriatic scales. J. Invest. Dermatol., 92, 515. (Abstract) 
29) Sheridan, J.F., Beck, M., Smith, C.C. \& Aurelian, L. (1987) Reactivation of herpes simplex virus is associated with production of a low molecular weight factor that inhibits lymphokine activity in vitro. J. Immunol., 138, 1234-1239.

30) Strieter, R.M., Kunkel, S.L., Schowell, H.J., Remick, D.G., Phan, S.H., Ward, P.A. \& Marks, R.M. (1989a) Endothelial cell gene expression of a neutrophil chemotactic factor by TNF- $\alpha$, LPS, and IL-1 $\beta$. Science, 243, 1467-1469.

31) Strieter, R.M., Phan, S.M., Showell, H.J., Remick, D.G., Lynch, J.P., Genord, M., Raiford, C., Eskandari, M., Marks, R.M. \& Kunkel, S.L. (1989b) Monokine-induced neutrophil chemotactic factor gene expression in human fibroblasts. J. Biol. Chem., 264, 10621-10626.

32) Takematsu, H. \& Tagami, H. (1990) Granulocyte-macrophage colony-stimulating factor in psoriasis. Dermatologica, 181, 16-20.

33) Takematsu, H., Terui, T., Ohkohchi, K., Tagami, H., Suzuki, R. \& Kumagai, K. (1986a) Presence of chemotactic peptides other than C5a anaphylatoxin in scales of psoriasis and sterile pustular dermatoses. Acta Derm. Venereol. (Stokh.), 66, 93-97.

34) Takematsu, H., Suzuki, R., Tagami, H. \& Kumagai, K. (1986b) Interleukin-1-like activity in horny layer extracts : Decreased activity in scale extracts of psoriasis and sterile pustular dermatoses. Dermatologica, 172, 236-240.

35) van Damme, J., van Beeumen, J., Conings, R., Decock, B. \& Billiau, A. (1989) Purification of granulocyte chemotactic peptide/interleukin-8 reveals N-terminal sequence heterogeneity similar to that of $\beta$-thromboglobulin. Eur. J. Biochem., 181, $337-344$.

36) Watanabe, K., Kinoshita, S. \& Nakagawa, H. (1989) Purification and characterization of cytokine-induced neutrophil chemoattractant produced by epithelioid cell line of normal rat kidney (NRK-52E cell). Biochem. Biophys. Res. Commun., 161, 10931099.

37) Yoshimura, T., Matsushima, K., Tanaka, S., Robinson, E.A., Appella, E., Oppeheim, J.J. \& Leonard, E.J. (1987) Purification of a human monocyte-derived neutrophil chemotactic factor that has peptide sequence similarity to other host defense cytokines. Proc. Natl. Acad. Sci. USA, 84, 9233-9237. 